\section{Notas sobre o realismo de Sérgio Ferro e Flávio Império}

Approching the realism of Sérgiio Ferro and Flávio Império

Felipe Araujo Contier*, Lívia Loureiro Garcia**

*Arquiteto urbanista pela FAU-USP (2009), Doutor pelo IAU-USP (2015) e professor de Teoria da História da Arquitetura na Faculdade de Arquitetura e Urbanismo da Universidade Presbiteriana Mackenzie. Organizou o livro “A história da arquitetura vista do canteiro” (GFAU, 2010), felipe.contier@mackenzie.br

${ }^{*}$ Cenógrafa, pesquisadora de cenografia brasileira, arquiteta e urbanista pela Universidade Presbiteriana Mackenzie (2006), mestra em Artes Visuais pela Universidade

Estadual de Campinas (2012). Leciona cenografia em cursos livres que visam desvelar os processos de criação do desenho e do espaço, livialou@hotmail.com

\section{Palavras-chave:}

Cenografia,

Arquitetura brutalista,

Artes plásticas.

\section{Keywords:}

Scenography,

Brutalist architecture,

Visual arts.

\section{Resumo}

Este texto pretende realizar uma aproximação ao realismo na produção

de Sérgio Ferro e Flávio Império. O tema foi abordado através de uma

análise geral do conceito, entrelaçando as reflexões dos arquitetos pin-

tores nos anos de 1960, algumas cenografias de Flávio Império para o

Teatro de Arena, e o debate crítico sobre arquitetura. Apesar das dife-

renças entre cada um dos campos, é possível notar uma convergência

em torno da cultura artística realista que os autores criticaram em reco-

nhecimento à realidade social brasileira.

\section{Abstract}

This text seeks to approach Brazilian realism in the 60's by looking at the thought and work of Sérgio Ferro and Flávio Império. After a general analysis of realism in visual arts, we examine how the intellectual orientation of Flávio Império's set design practice at Arena Theatre company and the critical debate on architecture led by Sérgio Ferro intertwine. It is possible to notice a convergence in their practice, although set in different fields, when we look at their critique of a realism that was not able to acknowledge Brazilian social reality.

\section{usjt}

\section{arq.urb}

número 29 | set - dez de 2020

Recebido: 06/01/2020

Aceito: 07/04/2020

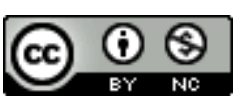




\section{Artes plásticas}

Poucos conceitos em história da arte foram tão usados, disputados e transformados por artistas, críticos e historiadores como o realismo. Ainda mais se consideradas as variantes regionais, cronológicas e artísticas: realismo poético, épico, fantástico, socialista, psicológico, neo, novo e nouveau.

É tomando o realismo como uma tradição artística constituída por movimentos plurais e contraditórios, engajados em compromissos políticos de suas épocas, que devemos compreender a recepção brasileira ao novo realismo da segunda metade da década de 1950 e seu impacto no grupo Arquitetura Nova.

Flávio Império e Sérgio Ferro formaram-se nesses anos em franco contato com a cultura artística paulistano, que era bastante atualizada. Em 1956, Flávio ingressou na FAU-USP e no curso de desenho da Escola de Artesanato do Museu de Arte Moderna de São Paulo. Neste mesmo ano iniciou os trabalhos com teatro na Comunidade Cristo Operário e nos anos seguintes se aproximou do Teatro de Arena. Sérgio foi incentivado a pintar por Pietro Maria Bardi quando ainda era estudante secundarista e logo que se formou arquiteto tornou-se professor assistente de Flávio Motta na USP e assistente de Ciccilo Matarazzo na organização das Bienais de São Paulo.

Os arquitetos pintavam em sintonia com a produção artística internacional, experimentando ecleticamente o informalismo, o tachismo ou a pop art daquele momento, representados nas Bienais de São Paulo, porém insistindo em conteúdos políticos que faltavam às obras estrangeiras.

Em 1965, Ferro e Império participaram da exposição coletiva Propostas 65, que tinha como objetivo debater "aspectos do realismo atual no Brasil"1, em iniciativa análoga à Opinião 65, realizada no MAM do Rio de Janeiro. Nos anos seguintes, Ferro publicou textos sobre artes plásticas, como "Pintura Nova" (1965), "Alberto Burri" (1966a), "A nova pintura e os símbolos" (1966b), "Ambiguidade da pop art: o buffalo II de Rauschenberg" (1967a), "Os limites da denúncia” (1967b) e "Enquan-

${ }^{1}$ Expressão usada no subtítulo do catálogo da exposição Propostas 65. Segundo depoimento de Sérgio Ferro aos autores, a exposição foi organizada no escritório dos arquitetos, com a participação de Waldemar Cordeiro, Lina Bardi e Mário Schenberg, e realizada na FAAP, onde Ferro e Império haviam sido contratados como professores do curso de artes plásticas. to os homens corajosos morrem" (1968); ; Império escreveu "A pintura nova tem a cara do cotidiano" (c.1965), além de diversos textos publicados em programas de espetáculos para os quais realizou a cenografia e o figurino.

Se o repertório formal dessa nova geração era eclético e internacional, do ponto de vista do conteúdo a produção artística brasileira do início da década de 1960 priorizou temas nacionais e sociais extraídos da história e da literatura moderna brasileiras, como é notável na música e no cinema - as expressões mais populares dessa cultura artística: Vidas secas, Morte e vida Severina, Macunaíma, Canudos e Lampião, Hans Staden e os tupinambás, Ganga Zumba, Zumbi e Tiradentes, Afrosambas e favelas. Esses temas históricos foram usados como matéria prima maleável e ressonante da conjuntura política e econômica do país. E, na medida em que essa produção artística se popularizava, as referências cruzadas permitiam amplificar e ressignificar uma obra pela outra, criar deslocamentos semânticos e subtextos que o público atento não deixava passar despercebido. Esse contexto artístico elevou o padrão crítico da cultura artística brasileira, que se aproximou da política, valorizou a vida cotidiana, o empirismo, o conhecimento vernáculo e a documentação da realidade.

\section{Teatro}

Em um caderno de anotações ${ }^{3}$, Flávio Império deixou os seguintes comentários sobre "a quarta parede" do teatro de palco italiano:

O teatro comportado entre quatro paredes, procura a empatia pela extrema semelhança, pelo simulacro da ficção dramática, pela identificação com as situações vividas pelos personagens na tessitura do drama. Esse anseio de reconstruir no espaço cênico o espaço ficcional do drama escrito encontrou na caixa mágica do chamado "teatro italiano" seus elementos de linguagem mais adequados e lá se instalou durante mais de quatro séculos com tanto conforto para as exigências do espetáculo como para as exigências da plateia que acabou por fundir a própria noção de teatro com esse tipo de edificação "a italiana" confundindo o fenômeno teatral com essa forma específica de manifestação. Reconhe-

${ }^{2}$ Como trabalho final de um curso de semiologia com Umberto Eco, realizado no Mackenzie em 1966, Ferro teria elaborado uma comparação entre o realismo de Honoré Daumier e o naturalismo de Gustave Courbet, inteiramente apoiado na teoria do romance de György Lukács. (FERRO, 2011, p.114).

${ }^{3}$ Os cadernos de Flávio Império foram digitalizados e transcritos e encontram-se no acervo do artista no IEB (Instituto de Estudos Brasileiros - USP) 
cida oficialmente como "manifestação cultural mais refinada." (IMPÉRIO, Caderno 5.5).

Segundo o autor, o teatro de palco italiano conserva as formas e signos de uma cultura "mumificada", protegida oficialmente, que perdeu a vitalidade, transformando-se numa alegoria do poder. O teatro da "caixa preta" alcança o mais elevado grau de simulação da "realidade" de uma cena, iludindo e confortando o público.

Em São Paulo, o Teatro Brasileiro de Comédia (TBC), criado em 1948 pelo industrial Franco Zampari, exerceu enorme influência na formação cultural da burguesia. O TBC trouxe uma nova perspectiva para o teatro brasileiro, com ampla infraestrutura para a realização de cenários, figurinos e todas as instalações necessárias para manter dois elencos e duas montagens simultâneas. Funcionando aos moldes de uma indústria, dirigiu-se para adular um público sedento por reconhecer no espaço da representação padrões sociais de uma vida sofisticada. Um teatro cuja artificialidade e ostentação formal supriam ideologicamente seu imaginário burguês (MAGALDI; VARGAS, 2001).

Apesar da familiaridade de Flávio Império com os códigos da tradição teatral de palco italiano, sua maior contribuição se deu junto a uma série de reações dissonantes; entre elas, de um grupo de artistas preocupado com a busca por um teatro que refletisse sobre a sociedade brasileira contemporânea. Neste contexto, nos anos de 1960, destacam-se o Teatro de Arena e o Teatro Oficina, com os quais Flávio Império trabalhou como cenógrafo e figurinista em diferentes oportunidades.

A Companhia de Teatro de Arena de São Paulo nasceu de um grupo de alunos formados na Escola de Arte Dramática (EAD), em 1953, dirigidos por José Renato. Naquele momento, era latente o desejo por um modelo diferente ao TBC, que representava uma linguagem internacional (IMPÉRIO, 1985). Desejava-se um teatro popular que fosse em direção ao público, onde ele estivesse, e capaz de produzir de forma mais econômica. De todo modo, as inovações formais e espaciais do Teatro de Arena inicialmente não partiram de questões políticas e ideológicas, visíveis nas encenações posteriores, ligadas à uma crítica sobre a sociedade brasileira, a sociedade de classes ou de abordagens marxistas (MOSTAÇO, 2016, p. 29).

Se por um lado, a inauguração da sede do Teatro de Arena na Rua Teodoro Baima, em 1954, implicou num recuo em relação a primeira atitude realista da Com- panhia em busca de um público mais amplo e representativo, por outro, permitiu que o espaço fosse utilizado para a realização de diversas atividades artísticas, assim como para o desenvolvimento de um pensamento cênico naquele espaço. A junção de componentes, alguns ainda amadores, do Teatro Paulista do Estudante (TPE) ao corpo fixo do Teatro de Arena, em 1956, provocou uma mudança na tônica geral do grupo ao trazer "uma reflexão crítica sobre o significado e sobre a realidade política que estava se vivendo" e sobre "a necessidade de transformação da realidade, em busca de uma esquerda, de uma participação, de uma militância" (PEIXOTO, 2004). A chegada de Augusto Boal, no mesmo ano, colaborou na busca por um teatro brasileiro, político e popular. Já na encenação de Ratos e Homens (1956), de John Steinbeck, Boal empregou o conceito de realismo seletivo:

os detalhes essenciais dão a ideia do todo. A encenação, toda ela, caracterizase por um despojamento absoluto, intencional e necessário. [...]. Em teatro de arena, mais talvez do que nos de proscênio, o que tem mais importância são as relações humanas. O que importa mais é a essência de cada cena, o sentido das coisas que são ditas e não tanto a maneira de dizê-las. $E$ isso implica em despojamento, em simplicidade, desde que se compreenda que simplicidade não é sinônimo de pobreza. (BOAL, 1956)

Nota-se uma aproximação conceitual entre Boal e Bertold Brecht, mesmo que isso ainda não se efetive formalmente na produção da imagem cênica. Fernando Peixoto esclarece a abordagem cenográfica defendida por Brecht:

um realismo seletivo: a reprodução de um local que ofereça elementos para o entendimento das relações entre os homens, destacando os que existem na realidade, mas que não são imediatamente visíveis após um simples olhar. Cabe ao cenógrafo realizar esta revelação da verdade. Deve sugerir. Com a condição de que estas sugestões apresentem um interesse histórico ou social superior ao oferecido pelo ambiente real. (PEIXOTO, 1974, p. 336)

As escolhas estéticas do grupo evidenciam a opção por um certo "realismo", ora considerado socialista, ora crítico, ora fotográfico. Esta variedade de leituras revela um caleidoscópio de concepções ideológicas, políticas e partidárias dos componentes do grupo (MOSTAÇO, 2016). Se o formato do Arena obrigou a criação de uma outra linguagem, na qual era impossível fugir do realismo (MIGLIACCIO, 2004), também possibilitou a presença de estudantes, amadores, de gente que dificilmente teria a chance de estar no palco criando artisticamente. Neste movi- 
mento há a semente de uma outra pedagogia, que tem a função de didatizar o processo e desmistificar a técnica artística.

Nesse período, Flávio Império, ainda estudante da FAU, teve sua primeira experiência de teatro na Comunidade Cristo Operário, trabalhando com os operários da fábrica-cooperativa de móveis Unilabor. O grupo de teatro construiu um tablado no qual faziam apresentações em lugares não convencionais como ginásios e sedes de clubes, numa configuração espacial próxima à formulação original do Teatro de Arena. Porém, o mais importante desta experiência para os trabalhos posteriores de Império no Arena, foi o convívio direto com a população que seria representada no Arena:

Esse período foi um dos mais ricos da minha vida por permitir uma convivência bastante íntima e afetiva com setores da população que só vim a encontrar depois, nas filas de ônibus, nos bares, mas sem nenhuma possibilidade de convívio mais profundo no plano humano. Restrito à convivência de minha classe social, passei a integrar a equipe do Teatro de Arena, desde os tempos de Eles Não Usam Black-Tie. Contestei durante o tempo todo o realismo meio fotográfico, que era a base do trabalho dos laboratórios de dramaturgia e interpretação. (IMPÉRIO, 1975, p. 40).

Eles não Usam Black-Tie (1958), de Gianfrancesco Guarnieri, direção de José Renato, foi concebida em meio a uma crise do Teatro de Arena e alterou em definitivo os seus rumos. $O$ texto com linhas realistas, quase naturalistas, traz à cena pela primeira vez o proletário como protagonista, com problemas e sentimentos próprios. Antes de Flávio Império, o cenário e o figurino eram uma junção de elementos realizada intuitivamente pelos componentes do grupo. Após sua chegada, a imagem cênica ganhou força poética e passou a ser elemento significante, conferindo aos espetáculos mais uma camada de leitura

Inicialmente para a construção dos elementos visuais da cena Flávio Império usava uma estrutura de pesquisa semelhante àquela dos Seminários de Dramaturgia e Interpretação (iniciado em 1958), que buscavam compreender o comportamento do brasileiro. Seguindo uma pesquisa quase "antropológica":

A mesma pesquisa que se fazia em literatura, através dos Seminários de dramaturgia ou em Laboratórios de interpretação, eu procurava fazer com a imagem em cenografia, procurando estudar o comportamento do brasileiro, através de elementos visuais, vendo candomblé, carnaval, todas as manifestações popula- res e documentando o que via, da forma que me era possível. Observava o modo pelo qual se tornava muito nítido a característica do estudante da época, ou do comerciante ou do industrial, ou do bancário. Observava como políticos se vestiam, como o povo se vestia no cotidiano. Desenvolvia um trabalho antropológico, trazendo para o teatro a imagem que tínhamos de nossa própria sociedade. Talvez tenha sido a primeira vez que se fez isso, de forma sistematizada. (IMPÉRIO, 1985).

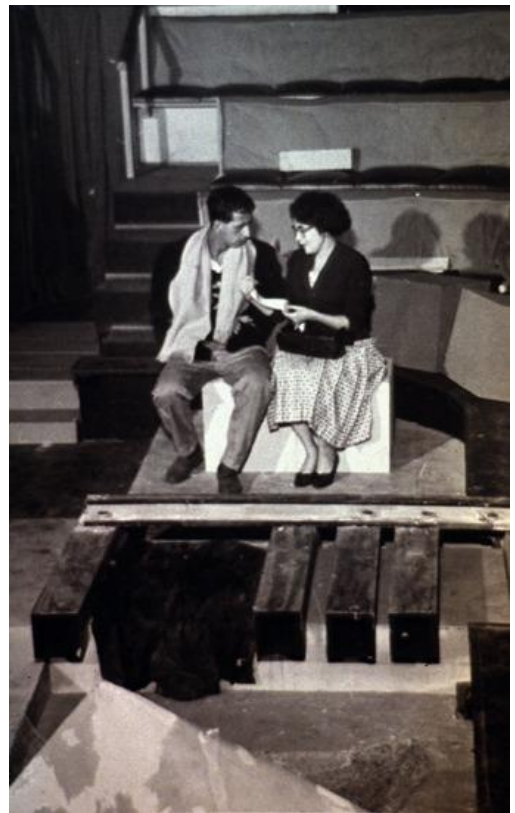

Figura 1: Gente como a gente, de Roberto Freire. Direção: Augusto Boal. Na fotografia: Flávio Migliaccio (Wilson) e Riva Nimitz (Jandira), 1959. Arquivo Sociedade Cultural Flávio Império. Disponível em Cd-Rom Arena Conta Arena 50 Anos.

Em 1959, Império trabalhou na composição gráfica de Chapetuba Futebol Clube, de Oduvaldo Vianna Filho, e nos dispositivos cênicos de Gente como a Gente, de Roberto Freire. Gente como a Gente (Figura 1) apresenta, segundo Boal (1959), "uma visão católica de um problema social", novamente trouxe ao palco o protagonismo de trabalhadores comuns como ferroviários e telefonistas. A despeito das controvérsias internas do processo de construção da peça (FREIRE, 2004) e de sua curta trajetória, observa-se a construção de uma imagem a partir da racionali- 
zação da arena. Flávio Império criou cinco cenários modulados: "Tudo era quadrado, reto, até os pregos da linha de ferro, ou eram cubos ou eram paralelepípedos" (BOAL, 2004). Ziembinski, com o desenho de luz, contribui para a criação de uma sucessão de quadros, que focavam apenas os personagens em ação. Com poucos recursos esses dispositivos cênicos orientavam os conteúdos formais de maneira direta e sintética, entrelaçando-se ao realismo da encenação.

Em 1961, Pintado de Alegre (Figura 2), de Flávio Migliaccio, seguiu uma linha de criação empírica, direcionada pelo texto, na qual os elementos cênicos eram utilizados a partir da necessidade interna dos personagens, valendo-se de elementos usados e desgastados, distanciando-se do limpo e do novo: "uma muleta adaptada à cama sem pé, a flor cobre o remendo" (IMPÉRIO, 1961). A composição de Flávio Império trilhava o mesmo caminho de Boal na direção da peça. Um "realismo impressionista", como classificou o cenógrafo, que fragmentou as cores e valorizou os detalhes em primeiro plano (IMPÉRIO, 1961) em busca de uma atmosfera que trazia à cena manifestações da vida urbana popular, não pelo que ela tivesse de "folclore", mas pela sua "realidade expressiva".

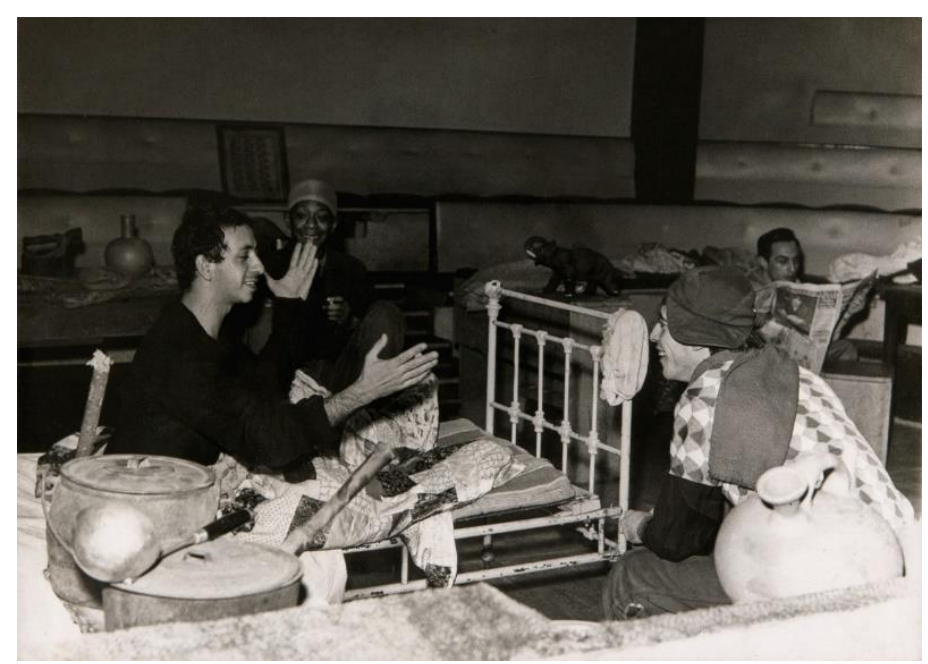

Figura 2: Pintado de Alegre, de Flávio Migliaccio. Direção: Augusto Boal. Ensaio com Flávio Migliaccio, Milton Gonçalves, Angelo Del Matto e Altamiro Martins, 1961. Fotografia de Benedito

$$
\text { Lima de Toledo. Acervo Particular. Disponível em }
$$
http://flavioimperio.com.br/galeria/509981/509999
Notas sobre o realismo de Sérgio Ferro e Flávio Império

Mesmo que, no Teatro de Arena, houvesse naquele momento um trabalho muito concentrado na produção de dramaturgias nacionais, o grupo não deixou de encenar textos internacionais. Os Fuzis da Mãe Carrar (1962), dirigida por José Renato, é uma peça dramática de Bertold Brecht, sobre os impactos do bombardeio de Guernica. A peça acontece em um tempo e espaço determinados e específicos: o tempo de assar um pão com a última farinha que resta a Sra. Carrar. O espaço, a casa de pescadores pobres, nela vivem a Sra. Carrar e seus dois filhos. No texto, questiona-se a noção de neutralidade, a mensagem é clara e didática: em uma situação de opressão, manter a neutralidade é caminhar ao lado do opressor. A cenografia de Flávio Império traz os elementos básicos para a representação do texto.

Na cenografia não há a sobreposição de elementos como em Pintado de Alegre, mas uma racionalidade sintética, o realismo seletivo de Brecht. Com os objetos mínimos e necessários para que se narre com verdade a situação dramática: o forno, a mesa e os bancos formando uma cruz, uma garrafa, meias a secarem sobre o forno, uma rede de pesca (Figura 3). O cenário não ilude a plateia nem romantiza os personagens em cena.

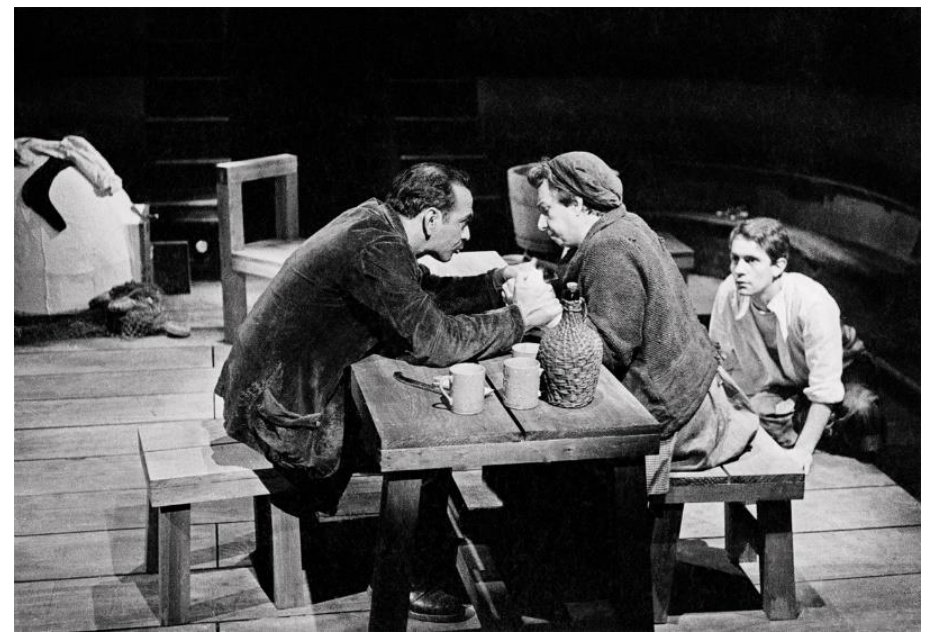

Figura 3. Os Fuzis da Mãe Carrar, de Bertolt Brecht. Direção: José Renato. Ensaio com Lima Duarte, Dina Lisboa e Paulo José. Fotografia de Benedito Lima de Toledo, 1962. Fonte: Acervo Flávio Império - IEB USP. Disponível em http://flavioimperio.com.br/galeria/507118/507132 
Este processo de captar a realidade ajudava na síntese e precisão da imagem cênica, criando uma resposta teatral e poética vivenciada no palco. Flávio "reunia um monte de fotografias, recortes de jornal, revistas, e aparentemente às vezes sem relação imediata [...] pedaço de tecido, fotografia, objeto". (FERRO, 2012).

O Melhor Juiz, o Rei (1963), de Lope de Vega, pertence à um grupo de montagens que no Arena levou o nome de Nacionalização dos Clássicos. Ao montar a peça, o grupo realizou uma adaptação do texto espanhol que se passa originalmente no século XVII. As mudanças no texto buscaram ecos na conjuntura brasileira. Para tanto, o terceiro ato da peça que trata do camponês que move uma ação judicial contra um nobre foi modificado. Ao final, um outro camponês, amigo do processante, entrava disfarçado de rei, em benefício do colega, aplicando a justiça. Se Lucrécia, a noiva, representava em Lope de Veja, o poder, na adaptação, ela conotava as questões relativas à terra e à reforma agrária.

No texto para o programa do espetáculo, desvela-se as escolhas para a concepção visual do espaço. Flávio Império (1963) afirma que a forma de produção em arquitetura, teatro e nas artes plásticas se distingue pelo tempo, espaço e "principalmente modo e preço da produção". O que faz necessariamente com que o artista se localize no "âmbito das possibilidades reais do 'instante histórico' (IMPÉRIO, 1963). Para ele, em todos os casos o artista deveria buscar a coerência com o próprio tempo e as possibilidades reais de um país subdesenvolvido.

Flávio Império nota que o fato de não "contarmos com bons artesãos" permite, por um lado, uma libertação, enquanto, por outro, lamenta a sua falta num contexto em que a industrialização não estava consolidada, em que a maior parte da produção era realizada por meios artesanais ou manufaturados: "O treino do mecanismo de projetar com peças já prontas é mínimo e a falta de qualidade e a escassez das mesmas são tomadas como uma limitação absoluta [...]" (IMPÉRIO, 1963). No TBC havia uma equipe de artesãos - costura, marcenaria etc. - prontos e capacitados a executar qualquer tipo de projeto, mas aquele tipo de produção era oposta aos anseios do Arena. Para produzir a imagem cênica Império explica que se na linguagem teatral empregava-se o objeto pelo seu "atributo", pelo seu símbolo, por aquilo que lhe é característico, tornava-se eficiente a aplicação de objetos prontos na imagem cênica visual. Mas, a falta de qualidade nos objetos prontos e de bons artesãos transformava aquilo que poderia ser eficiente, numa
Notas sobre o realismo de Sérgio Ferro e Flávio Império

dificuldade. $\mathrm{O}$ artista continua o pensamento para justificar suas escolhas no teatro:

Se tomarmos um objeto qualquer, feito para um determinado fim, e juntarmos a ele outro, o que da reunião resulta nem sempre é uma soma. Muitas vezes, e é desses casos que tratamos, o resultado é um terceiro. Como na imagem cênica sempre é possível dominar-se o todo e as partes, o objeto isolado pode ter um sentido inteiramente diferente do objeto no todo.

Assim sendo podemos tentar colocar o termo 'criação', como algo menos esotérico, e inexplicável, tornando-o mais simples, com sentido mais objetivo de organização, ordenação, sistematização, uma forma de planejamento. (IMPÉRIO, 1963).

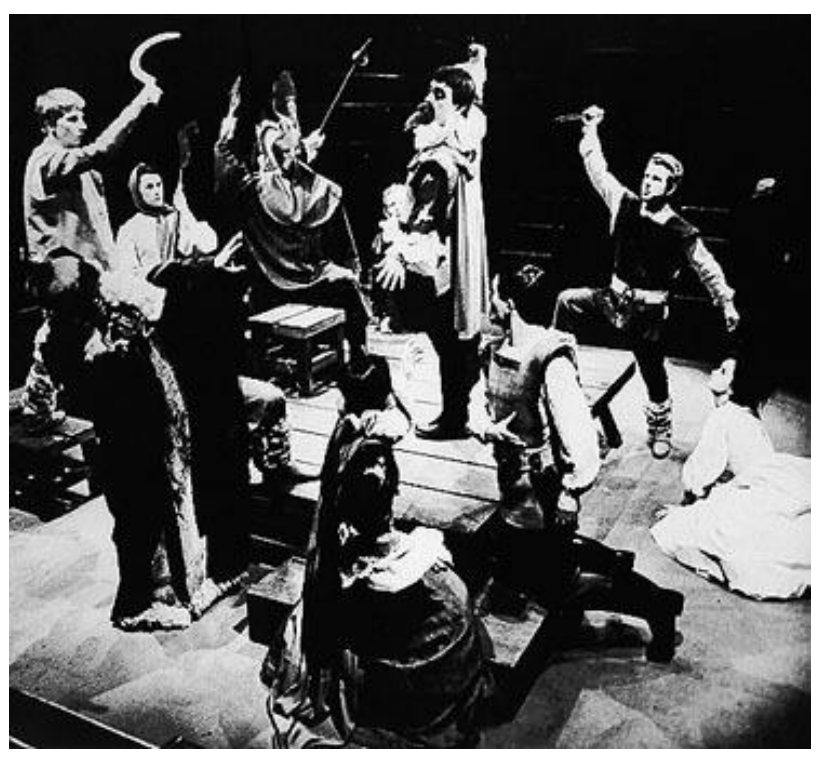

Figura 4. O Melhor Juiz, o Rei, de Lope de Vega. Adaptação: Augusto Boal Gianfrancesco Guarnieri, Paulo José. Direção: Augusto Boal. Ensaio com Gianfrancesco Guarnieri (Pelaio), Alexan-

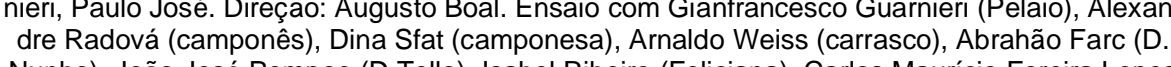
Nunho), João José Pompeo (D.Tello), Isabel Ribeiro (Feliciana), Carlos Maurício Fereira Lopes (soldado), Juca de Oliveira (Sancho) e Joana Fomm (Elvira). Arquivo Multimeios / IDART - 1963. Disponível em CD-ROM Arena conta Arena 50 anos

O texto deixa explícito um procedimento que Império usou em vários momentos de sua trajetória. Procedimento também explorado nas artes visuais desde o início do século XX: a aplicação de materiais prontos e não convencionais. Além de criar 
significados cênicos, há a ideia de destituição da aura artística tradicional. O artista considera o artesanato, a manufatura dentro de um espaço e de um tempo histórico, sem abstrair ou generalizar a produção artesanal (Figura 4).

Cabe ilustrar essas ideias com um figurino: para compor os personagens Flávio Império usou elementos prontos, como bota de borracha, feltro acústico, tecido de algodão e estopa, renda pintada, que com a sobreposição de camadas podem ser compreendidas como conjunto de uma indumentária do século XVII, dando a ideia de um "teatro 'teatral' (figura 5). O teatral seria não apenas um efeito de distanciamento, mas um apelo à capacidade do espectador de aceitar e apreciar uma verdade artística" (LIMA, 1997).

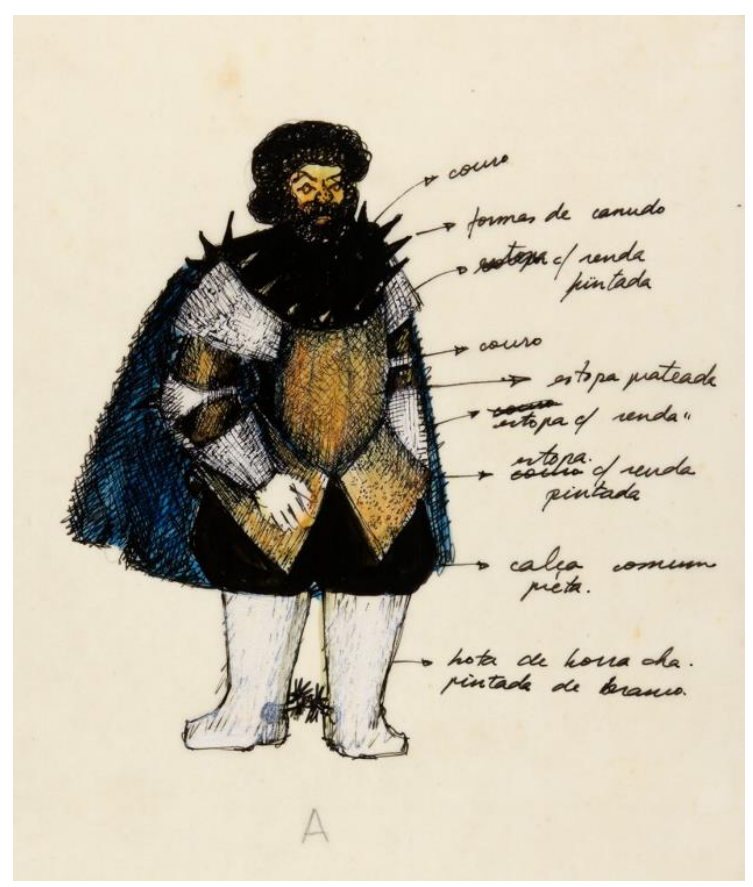

Figura 5. O Melhor Juiz, o Rei de Lope, de Vega. Adaptação: Augusto Boal Gianfrancesco Guarnieri, Paulo José. Direção: Augusto Boal. Projeto de figurino de Flávio Império. Nanquim sobre papel. Acervo Flávio Império- IEB USP. Disponível em http://flavioimperio.com.br/galeria/507437/507520
Após o golpe militar, as esquerdas esforçaram-se em suprimir as contradições internas, ajustando suas forças contra o fascismo. Setores teatrais logo se mobilizaram para a criar de um "modelo" de arte de resistência. Após a destruição do CPC (1964), alguns de seus integrantes uniram-se para formar um grupo de arte de protesto, o Opinião. A ação desses espetáculos foi comparada por Mostaço (2016) aos rituais, nos quais a mitologia interna é transmitida em códigos específicos e implícita para o público. Existindo uma identificação entre os atores e espectadores, na qual ambos representam o povo, seguindo o plano ideológico de arte nacional-popular do PCB. Enquanto Boal dirigia Opinião no Rio de Janeiro, Guarnieri juntava o elenco do Arena para a criação de um espetáculo com os mesmos padrões do grupo carioca, mas baseado numa situação dramática mais consistente: Arena Conta Zumbi (1965).

Ao voltar para São Paulo, Boal desenvolve o sistema coringa, no qual os atores transitam de personagens em cena, permitindo que cada ator atue em diversos papéis e situações. Com projeções de mapas e fotos pretendia-se elucidar as questões tratadas pelo texto, na falta deste material explicativo, a narrativa é interrompida e anunciava-se a falta, o "resultado assemelhava-se a um seminário acadêmico, uma dramatização feita por alunos para uma aula ilustrada" (MOSTAÇO, 2016, p. 104).

Com Arena Conta Zumbi inaugura-se na companhia os estudos a respeito do herói positivo. $O$ espetáculo foi fonte de identificação profunda entre públicoplateia, na qual havia uma espécie de circuito fechado, uma catarse purificadora engloba os dois em uma espécie de ritual de protesto. Para a realizar Arena conta Zumbi, Flávio Império já estava afastado do grupo e do processo de criação, e, ao chegar, criticou o espetáculo:

Quando eu cheguei estava pronto. [...] Eu não participei do Zumbi. Eu só vi o espetáculo. Ainda estava cru, mas estava todo estruturado. E quando acabou eu morri de rir. Era uma coisa tão engraçada! Eu falei: 'Parece um bando de intelectuais, no tapete do pai, tomando uísque e conversando sobre o povo'. [...] Eu mexi um pouco na estrutura do teatro para o Zumbi. E resolvi revestir o chão com um tapete caro e bem felpudo, um tapete de náilon, inclusive brilhante. Uma coisa cafona de turco rico. Porque eu achava que os pais de todos nós eram turcos ricos. Era um tapete vermelho bem grande, que a gente até ganhou, e que forrava o palco inteiro. Era vermelho de propósito de brincadeira. A roupa de todos eles era uma roupa que a pequena burguesia usava para ir às universida- 
des: calça Lee e blusa de cor. Se não me engano eles eram sete que cantavam, então eu peguei as sete cores do arco-íris, cada um ficou com uma cor, e a calça era uma calça de brim branca, uma calça Lee crua, não era branca. Ficou essa ideia de que a peça se passava como se fosse na sala de visitas de uma família burguesa e rica, contando a história do povo. (IMPÉRIO, 1985).

Aqui fica claro um realismo épico que além de criticar a própria encenação vai buscar a identificação do público com quem se fala e não sobre o qual se fala. Os figurinos e o cenário são espelho da plateia. Isso ao mesmo tempo colabora no processo de identificação como traz uma carga épica à encenação (figura 6).

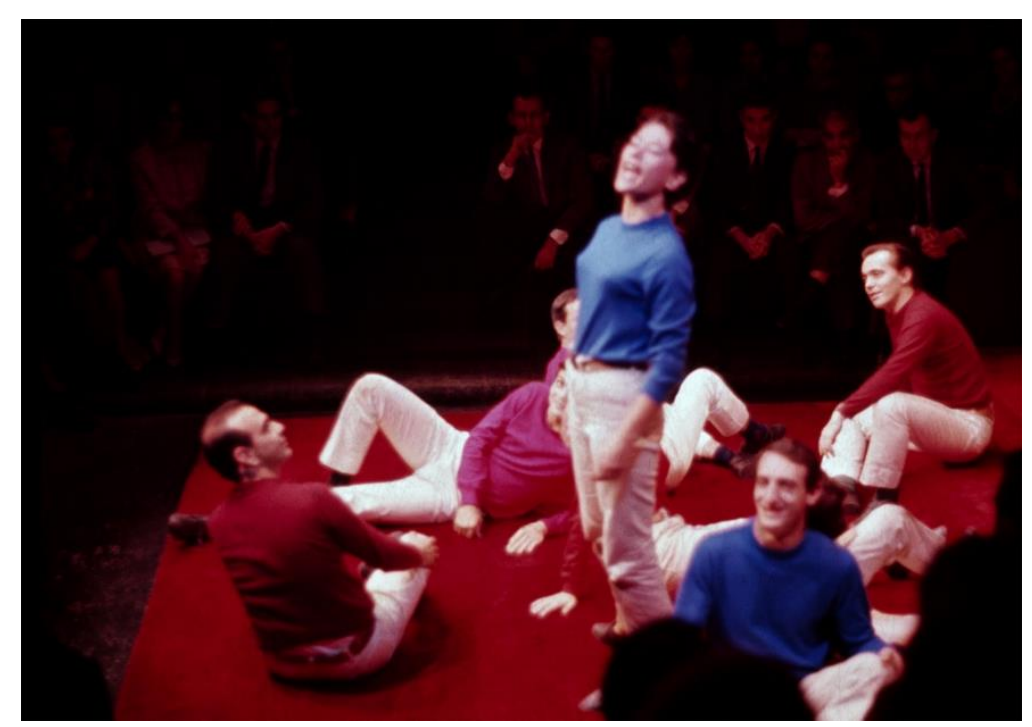

Figura 6. Arena conta Zumbi, de Augusto Boal e Gianfrancesco Guarnieri. Direção: Augusto Boal. Na imagem: Lima Duarte, Dina Sfat, Anthero de Oliveira, Marília Medalha, Chant Dessian e Gianfranscesco Guarnieri. Fotografia de Benedito Lima de Toledo, 1965. Acervo Flávio Império IEB USP. Disponível em http://flavioimperio.com.br/galeria/507872/507878

No palco mínimo do centro de São Paulo estabelece-se um projeto por uma estética específica, sem a criação dos simulacros. Um projeto diretamente articulado com a realidade social e as escolhas políticas do grupo, a escolha de uma estética é também ética. Para Amélia Hamburger aquilo que liga o Arena ao trabalho de Flávio Império é o "uso contínuo da intuição, da experimentação, da análise crítica;
Notas sobre o realismo de Sérgio Ferro e Flávio Império

sentir-se povo brasileiro, ter uma visão antropológica das manifestações do povo; estar sempre a destrinchar e rejeitar o autoritarismo nas relações entre os indivíduos e entre o indivíduo e o coletivo". (HAMBURGER, 2004, p. 2)

O "despojamento" da uma imagem cênica e a criação de uma cenografia própria para a arena, está ligada ao trabalho de Flávio Império. O trabalho de maneira artesanal, ligado ao material mais próximo, mais cotidiano, facilita "a compreensão das coisas" (VARGAS, 1997, p.59). Revela, traços do inacabado, do informal, incluindo e recorrendo ao espectador para completar, com sua imaginação, os espaços da encenação. Conseguindo com isso uma síntese da imagem, tão necessária a um teatro com a conformação espacial do Teatro de Arena, neste sentido cria atmosferas cênicas fortemente envolventes. Que dialogam com a situação brasileira, com a busca por uma forma de expressão distendida dos moldes europeus e crítica ao modelo desenvolvimentista.

\section{Arquitetura}

Na segunda metade da década de 1950, críticas internacionais à leviandade formalista da arquitetura moderna brasileira (BILL, 1953), à ausência de planejamento urbano e predomínio da especulação imobiliária (ARGAN, 1954), e à irracional velocidade no desenvolvimento de uma expressão própria (GIEDION, 1956), começavam a ecoar entre os jovens arquitetos que passaram a questionar os recursos artificiais e o descompasso do modernismo arquitetônico com a realidade brasileira.

Essas críticas, vindas de especialistas respeitados e identificados com o modernismo internacional, foram praticamente ignoradas pela geração anterior. Vilanova Artigas, defendeu Oscar Niemeyer de tais críticas, justificando uma experiência brasileira negativa com o funcionalismo por seu caráter cosmopolita e antipopular (ARTIGAS, 1953), e mesmo após tomar contato direto com o neoclassicismo praticado na URSS, em 1952 e 1953, insistiu para que o realismo socialista reconhecesse no modernismo icônico de Niemeyer "a posição certa, a posição materialista”, em relação aos anseios populares dos brasileiros (ARTIGAS, 1954). 
Em conferência de 1954, traduzida para o português e publicada pela revista Fundamentos $^{4}$ em 1955, o líder do Partido Comunista soviético, Nikita Kruschev, por sua vez, dirigiu críticas à arquitetura soviética, afirmando que o realismo socialista deveria se comprometer mais com as dinâmicas econômicas e necessidades materiais da população do que com a aparência. Kruschev propunha aos arquitetos que formulassem uma nova poética baseada nos elementos da própria construção e que buscassem uma transformação produtiva no sentido da industrialização. (KRUSCHEV, 1955)

Foi somente após o pronunciamento de Kruschev sobre a falta de realismo do realismo socialista que os arquitetos do Partido Comunista do Brasil, sendo Niemeyer e Artigas os mais emblemáticos desse processo, revisaram suas posições. O "depoimento" de Niemeyer (1958) e o apoio de Artigas a ele (1958) fazem parte desse movimento. Mas é sobretudo na prática projetual que podemos observar a virada realista de cada um. Enquanto Niemeyer argumentava estar, desde Brasília, comprometido com formas mais aderidas à própria estrutura e estas mais sintéticas, evitando múltiplas soluções em um único projeto, Vilanova Artigas, se reconciliava com seu passado Wrightiano e sua moral que pregava a "verdade dos materiais", explorando plasticamente o concreto aparente nas edificações.

O concreto aparente e a crescente dramaticidade das estruturas - concentração de cargas em poucos apoios, grandes balanços, estruturas musculosas, lajes nervuradas aparentes etc. - fazem parte, obviamente, de um arsenal arquitetônico festejado e difundido internacionalmente no final da década de 1950, e muito identificado com a obra de Le Corbusier no pós-guerras. Essa nova modalidade de realismo arquitetônico fez escolas ao redor do mundo e suscitou as mais diversas, e por vezes antagônicas, apropriações intelectuais. No quadro brasileiro em especial, e paulista em particular, Joaquim Guedes foi dois primeiros a adotá-la e a justificativa predominante de seu emprego foi da economia, do bem comum e da pertinência à realidade histórica e social brasileira.

Artigas rapidamente trocou o emprego inicialmente decorativo do concreto armado, visível na fachada da casa Olga Baeta, de 1956 (figura 7), por uma ênfase nos elementos estruturais em seus projetos para escolas, casas e clubes nos anos

${ }^{4}$ Revista ligada ao Partido Comunista do Brasil, editada pela Editora Brasiliense.
Notas sobre o realismo de Sérgio Ferro e Flávio Império

seguintes: linhas diagonais correspondentes aos esforços horizontais, continuidade do sistema fundação-pilar-empena-cobertura, rótulas móveis, afinamento das arestas e a multifuncionalidade dos pilares e vigas que serviam também à proteção solar, captação de água da chuva etc. Em 1960 o termo "brutalista" já era empregado para designar a obra de Artigas (ALFIERI, 1960), que convergia apropriadamente para a continuidade de uma narrativa iniciada uma década antes, que destacava a sua moral severa, sua racionalidade de engenheiro-arquiteto, sua economia de linguagem, sua atitude anti-burguesa e seu realismo (p. ex. BARDI, 1950).

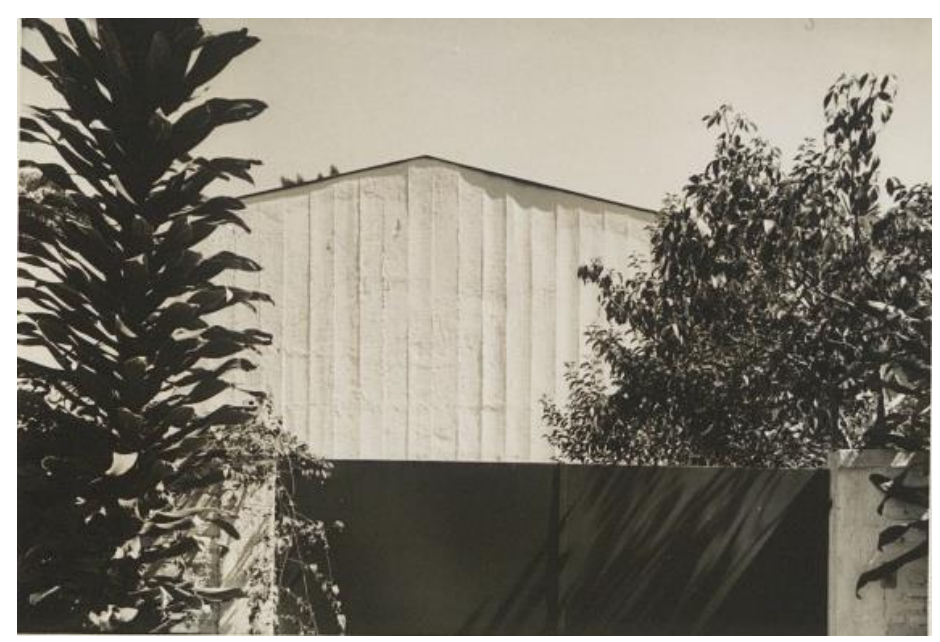

Figura 7. Fachada da residência Olga Baeta. Projeto de João Vilanova Artigas e Carlos Cascaldi, Butantã, São Paulo, 1956. Foto: autor desconhecido. Acervo da Biblioteca da FAUUSP.

Mas se Artigas se tornou um dos nomes de maior destaque da arquitetura brasileira na década de 1960, isso não quer dizer que sua obra fosse isolada ou excepcional. Ao contrário, sua projeção individual foi sustentada por um conjunto de arquitetos, entre os quais muitos de seus alunos e colegas de docência - Flávio, Sérgio e Rodrigo, inclusive -, cujos projetos buscavam maior objetividade por um lado, e a consolidação de uma nova linguagem, por outro (Figura 8). 


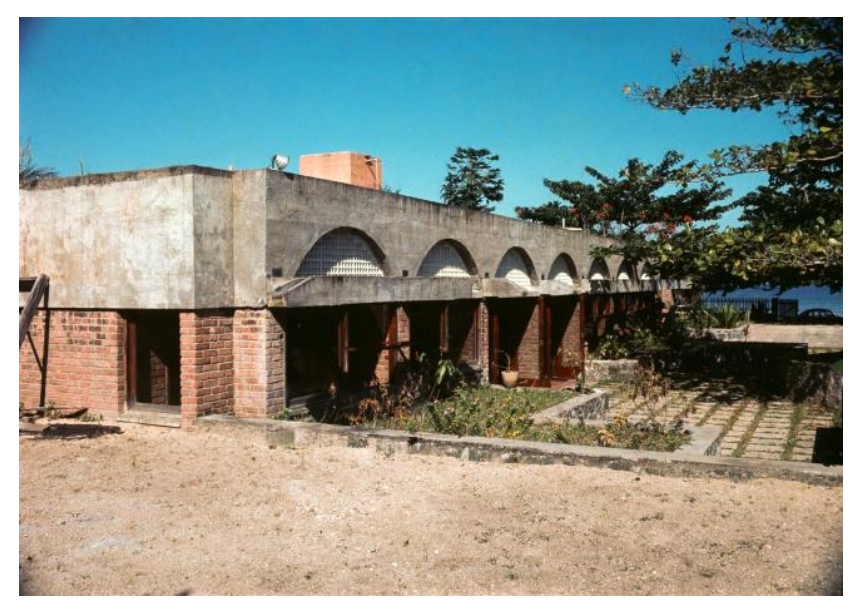

Figura 8. Residência Simon Fausto. Projeto de Flávio Império, Ubatuba, 1961. Foto: Benedito Lima de Toledo. Arquivo Flávio Império - IEB USP. Disponível em http://www.flavioimperio.com.br/galeria/505589/509929.

Esse primeiro brutalismo, que primou pela didatização, pela racionalização da construção e pela economia geradora de uma expressão formal sem concessões a representações ilusórias de uma sociedade burguesa esclarecida, estava relacionado à cultura artística realista daquele momento e seu contexto desenvolvimentista, com expectativas de profundas reformas sociais. Ainda não havia tropicalismo, e o que se via no cinema e no teatro nacionais eram reflexões ásperas sobre os impasses do país e a situação dos excluídos da modernidade. Os arquitetos igualmente pareciam reconhecer o subdesenvolvimento do país, seus limites em termos de materiais e mão de obra, que os conduzia para uma convergência programática em torno da baixa tecnologia. Esses mesmos arquitetos se mobilizaram para defender e dar protagonismo à população trabalhadora - que estava sendo rapidamente deslocada para as periferias das regiões metropolitana brasileira -, através, por exemplo, das pautas da reforma urbana e da habitação social. (BONDUKI; KOURY, 2010)

Se as residências unifamiliares burguesas representavam a maioria dos encargos desses arquitetos, nas quais ensaiavam-se soluções comuns, os projetos para as obras do Plano de Ação do Governo do Estado (1959-1963), articulados entre o $\mathrm{IAB} / \mathrm{SP}$ e o governo, representaram uma oportunidade inédita para a nova gera- ção "de orientação racional em São Paulo" difundir, através do Estado, os novos princípios estéticos. Preocupados com as grandes necessidades coletivas, muitos puderam construir obras públicas com os instrumentos que, em tese, estavam prontos "para organizar o espaço de um outro tempo mais humano" (FERRO, 1967c). É o que o próprio Sérgio Ferro reconhece, possivelmente incluindo-se entre os novos arquitetos dessa geração.

Nesse mesmo texto, porém, Ferro conclui que o golpe de 1964 teria revelado a ilusão da perspectiva de transformação social a partir da estética. E avança, como se sabe, para uma crítica radical aos caminhos desse "brutalismo caboclo", que traía o próprio realismo arquitetônico que o justificaria, transformando-se numa compensação para a frustração com a realidade, da qual emergiram como sintomas a arbitrariedade, o formalismo vazio, o caráter hermético - autorreferente e antipopular - e a radicalização de uma suposta ética austera, incompatível com a objetividade das obras (Figura 9).

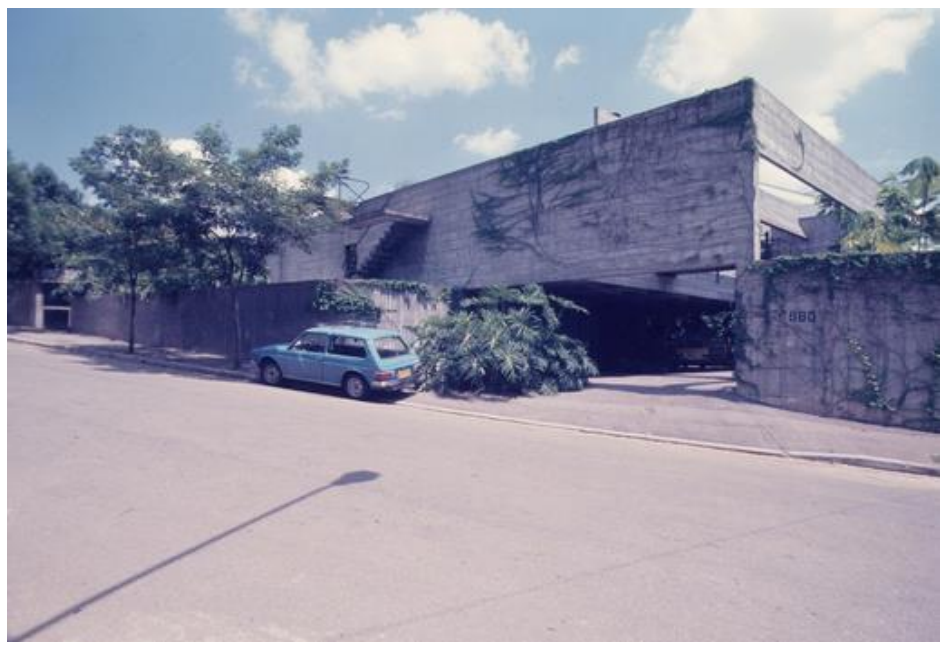

Figura 9. Residência Fernando Millan. Projeto de Paulo Mendes da Rocha, Morumbi, São Paulo, 1970. Foto: Hugo Segawa. Acervo da Biblioteca da FAUUSP.

Para além da crítica, Ferro apontava para a necessidade de uma arquitetura mais próxima ao que Flávio Império construía na cenografia e no teatro: a volta da obje- 
tividade na construção, aprofundando-se na compreensão de sua própria realidade, e dos símbolos no lugar dos sinais ${ }^{5}$.(Figura 10)

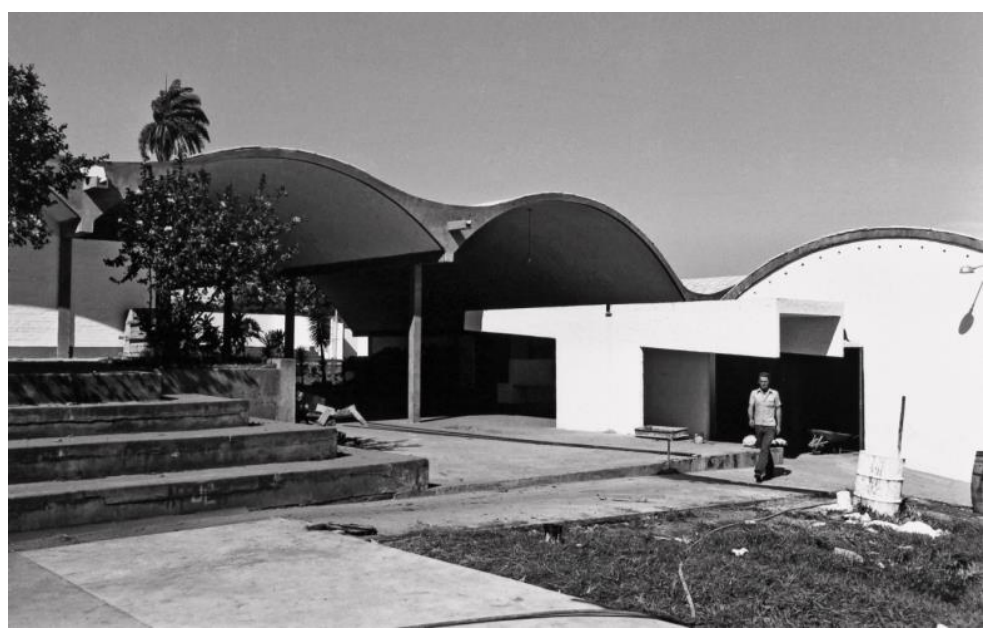

Figura 10. Ginásio Estadual e Escola Normal. Projeto de Rodrigo Lefèvre, Sérgio Ferro e Flávio Império, 1966-1967. Foto Rodrigo Lefèvre. Acervo da Biblioteca da FAUUSP.

Em "A casa popular", (1969), seu último texto sobre arquitetura escrito no Brasil, Ferro se afasta ainda mais das questões programáticas do brutalismo paulista, que a seu ver estavam restritas à um mercado de luxo apesar do discurso social, para abranger um conjunto mais representativo da realidade, no qual a autoconstrução era a regra e o mercado de massas era estreito.

No final da década de 1960 a teoria marxista se tornou mais presente nos textos de Ferro e guiou seu entendimento sobre a arquitetura como parte da indústria da construção, que por sua vez é parte da economia política. Essa compreensão ampla e sistemática da profissão alimentou a conhecida crise entre arquitetos "de prancheta" e críticos. Apesar dos contratempos desse debate, nem sempre produtivo, o realismo de Ferro deixou um fabuloso legado teórico para as pesquisas da

${ }^{5}$ Símbolos seriam formas de participação, pois surgem da "apreensão de alguma coisa existente, de conteúdos dispersos mas reais", em oposição ao sinal, que seria a "adição arbitrária de um conteúdo a uma forma". (FERRO, 1967)
FAUUSP, que ao longo da década de 1960 se tornaram mais atentas à realidade das cidades brasileiras e da construção.

\section{Conclusão}

Nestas notas sobre o realismo de Ferro e Império, buscamos aproximar atuações em campos que os próprios autores fazem questão de distinguir, muito embora atuassem em várias frentes. Veja-se, por exemplo, a constante comparação feita por Ferro entre o trabalho livre nas artes plásticas e o trabalho heterônomo na arquitetura. Essa distinção também deve ser feita em relação ao teatro, no qual a posição hierárquica do arquiteto, no sentido do controle da totalidade, corresponde ao do encenador naquele período. $O$ cenógrafo era praticamente o mestre de obras, uma ponte entre o encenador e os operários-fazedores, cuja mão desaparecia no teatro ilusionista para dar luz aos conceitos do diretor. No Teatro de Arena, Flávio Império promoveu o papel do cenógrafo-fazedor, que ele continuou sendo, para o de um participante das decisões de direção, que determinam o sentido da obra na medida em que a cenografia aparece e revela um trabalho autônomo que carrega uma poesia própria.

Flávio Império e Sérgio Ferro mantiveram uma relação crítica com a cultura artística realista da qual participaram, seja em relação ao realismo do Teatro de Arena, seja em relação ao brutalismo arquitetônico. Suas posições, apontam para uma correção do realismo, sem abdicar de sua perspectiva artística. $O$ que ambos criticavam era didatismo esquemático e forçado, a excessiva racionalização e o economismo injustificável em certas obras. Eles defendiam que os artistas se mantivessem engajados na dinâmica cultural viva e mutável, portanto, flexíveis e curiosos do ponto de vista formal e contrários aos arbítrios estilísticos. Que resistissem à autossatisfação provocada pelo sucesso afiançado pelas classes médias e intelectualizadas e superassem a mera representação do povo permitindo a efetiva participação popular. 


\section{Referências}

ALFIERI, Bruno. João Vilanova Artigas: ricerca brutalista. Zodiac, Milão, n. 6, 1960.

ARGAN, Giulio Carlo. Arquitetura moderna no Brasil [1954], In: XAVIER, Alberto (org.). Depoimentos de uma geração: arquitetura moderna brasileira. São Paulo: Cosac \& Naify, 2003.

ARTIGAS, João B. Vilanova. Brazilian Experience. Arkitekten, Arkitektens Forlag, Kopenhagen, ano 4, n. 20, maio 1953.

ARTIGAS, João B. Vilanova. Considerações sobre arquitetura brasileira [1954]. In: Caminhos da arquitetura. São Paulo: Cosac Naify, 2004.

ARTIGAS, João B. Vilanova. Revisão crítica de Niemeyer. Acrópole, São Paulo, n. 237, julho 1958.

BARDI, Lina. Casas de Vilanova Artigas. Habitat, São Paulo, n, 1, out-dez 1950, Republicado em XAVIER, Alberto (org). Depoimentos de uma geração: arquitetura moderna brasileira. São Paulo: Cosac Naify, 2003.

BILL, Max. A nossa moderna arquitetura. Manchete, Rio de Janeiro, 13 de julho de 1953.

BOAL, Augusto. Ratos e Homens. Texto no programa do espetáculo. São Paulo: Teatro de Arena, 1956. In: TEIXEIRA, Isabel (Org.). Arena Conta Arena 50 Anos. CD-ROM. São Paulo: Cia. Livre e Cooperativa Paulista de Teatro, 2005.

BOAL, Augusto. Gente como a gente. Texto no programa do espetáculo. São Paulo: Teatro de Arena, 1959. In: TEIXEIRA, Isabel (Org.). Arena Conta Arena 50 Anos. CD-ROM. São Paulo: Cia. Livre e Cooperativa Paulista de Teatro, 2005.

BOAL, Augusto. Depoimento para o Projeto Arena Conta Arena 50 Anos, ocorrido em 15 de setembro de 2004. In.: TEIXEIRA, Isabel (Org.). Arena Conta Arena 50 Anos. CD-ROM. São Paulo: Cia. Livre e Cooperativa Paulista de Teatro, 2005.

BONDUKI, Nabil; KOURY, Ana Paula. Das reformas de base ao BNH. As propostas do Seminário de Habitação e Reforma Urbana. Arquitextos, São Paulo, ano 10, n. 120.02, maio $2010 . \quad$ Disponível em www.vitruvius.com.br/revistas/read/arquitextos/10.120/3432.
FERRO, Sérgio. Pintura Nova. Publicado no catálogo da exposição Propostas 65. São Paulo: Fundação Armando Álvares penteado, 1965.

FERRO, Sérgio. Alberto Burri. O arquiteto. São Paulo, n. 1, jan. 1966a.

FERRO, Sérgio. A nova pintura e os símbolos. 0 arquiteto. São Paulo, n. 2, mar. $1966 \mathrm{~b}$.

FERRO, Sérgio. Ambiguidade da pop art: o buffalo II de Rauschenberg. Galeria de Arte Moderna, n. 3, 1967a.

FERRO, Sérgio. Os limites da denúncia. Rex Time, São Paulo, n. 4, 1967b

FERRO, Sérgio. Arquitetura Nova. Teoria e prática, São Paulo, n. 1, 1967c.

FERRO, Sérgio. Enquanto os homens corajosos morrem. aParte, São Paulo, TUSP, n. 1, 1968.

FERRO. Sérgio. A casa popular (1969). Republicado como "A produção da casa no Brasil”. In: Arquitetura e trabalho livre. São Paulo: Cosac \& Naify, 2006.

FERRO, Sérgio. Entrevista publicada em CONTIER, Felipe. História da Arquitetura e projeto da história. Desígnio, São Paulo, Annablume, n.11/12, p. 113-126, mar. 2011.

FERRO, Sérgio. Entrevista publicada em GUIMARAES, Andreas; CONTIER, Felipe; LOUREIRO, Lívia. "Flávio Império e as múltiplas facetas de um projeto brasileiro" Entrevista, São Paulo, ano 13, n. 051.01, jul. 2012. Disponível em www.vitruvius.com.br/revistas/read/entrevista/11.051/4405.

FREIRE, Roberto. Entrevista para o Projeto Arena Conta Arena 50 Anos, ocorrido em 14 de outubro de 2004. In: TEIXEIRA, Isabel (Org.). Arena Conta Arena 50 Anos. CD-ROM. São Paulo: Cia. Livre e Cooperativa Paulista de Teatro, 2005.

GIEDION, Sigfried. Prefácio [1956], In: MINDLIN, Henrique. Arquitetura moderna no Brasil. Rio de Janeiro: Aeroplano, 1999.

HAMBURGER, Amélia Império. A cenografia do Arena - Flávio Império. Palestra para o Projeto Arena conta Arena 50 Anos. Transcrição da palestra ocorrida em 31 de agosto de 2004. In: TEIXEIRA, Isabel (Org.). Arena Conta Arena 50 Anos. CD-ROM. São Paulo: Cia. Livre e Cooperativa Paulista de Teatro, 2005. 
IMPÉRIO, Flávio. Texto para o programa do espetáculo Pintado de Alegre. São Paulo: Teatro de Arena, 1961. Disponível em www.flavioimperio.com.br/galeria/509981/509990.

IMPÉRIO, Flávio. Uma boa experiência. Texto para o programa do espetáculo Melhor Juiz o Rei. São Paulo: Teatro de Arena, 1963. Disponível em: www.flavioimperio.com.br/galeria/507437/511385.

IMPÉRIO, Flávio. A pintura nova tem a cara do cotidiano, (c.1965). Disponível em www.flavioimperio.com.br/galeria/512786/512791.

IMPÉRIO, Flávio. Depoimento de Flávio Império a Fernanda Perracini Millani. 1975. In: KATZ, Renina e HAMBURGER, Amélia Império (orgs.). Flávio Império. Artistas Brasileiros. São Paulo: Edusp, 1999.

IMPÉRIO, Flávio. Depoimento de Flávio Império a Professora Margot Milleret, Dept. of Spanish \& Portuguese, Vanderbilt University, Nashvill, Tennessee, 1985. Editado por Maria Thereza Vargas São Paulo, 2012. Disponível em: www.flavioimperio.com.br/galeria/511162/511163.

KRUSCHEV, Nikita. Rumos da arquitetura soviética. Fundamentos, ano VII, n. 39, nov. 1955.

LIMA, Mariângela Alves. Flávio Império e a cenografia do teatro brasileiro, 1997. In: KATZ, Renina e HAMBURGER, Amélia Império (orgs.). Flávio Império. Artistas Brasileiros. São Paulo: Edusp, 1999.

MAGALDI, Sábato; VARGAS, Maria Thereza. Cem anos de teatro em São Paulo. São Paulo: Editora Senac, 2001.

MIGLIACCIO, Flávio; GERTEL, Vera. Depoimento para o Projeto Arena Conta Arena 50 Anos, ocorrido em 1 de setembro de 2004. In: TEIXEIRA, Isabel (Org.). Arena Conta Arena 50 Anos. CD-ROM. São Paulo: Cia. Livre e Cooperativa Paulista de Teatro, 2005.

MOSTAÇO, Eldécio. Teatro e política, Arena, Oficina e Opinião. São Paulo: Annablume, 2016.

NIEMEYER, Oscar. Depoimento [1958]. In: XAVIER, Alberto (org). Depoimentos de uma geração: arquitetura moderna brasileira. São Paulo: Cosac Naify,
Notas sobre o realismo de Sérgio Ferro e Flávio Império 2003.PEIXOTO, Fernando. Brecht Vida e Obra. São Paulo, Paz e Terra, 1974.

PEIXOTO, Fernando. O legado de um mito. Transcrição de palestra ocorrida em 17 de agosto de 2004. Projeto Arena conta Arena 50 Anos. In: TEIXEIRA, Isabel (Org.). Arena Conta Arena 50 Anos. CD-ROM. São Paulo: Cia. Livre e Cooperativa Paulista de Teatro, 2005.

VARGAS, Maria Thereza. Texto para o programa da exposição Flávio Império em cena. São Paulo: SESC, 1997 